\title{
Artificial Intelligence for Fashion Design
}

\author{
Fredrick Shaap* \\ Qiueue Research, USA
}

Submission: July 14, 2020; Published: July 23, 2020

*Corresponding author: Fredrick Shaap, President, Qiueue Research, 401 Congress Ave. Austin, Texas, USA

\begin{abstract}
This article provides a brief review of the artificial intelligence use cases in fashion industry in general and for fashion design in particular The main related cognitive technologies along with examples of their key application areas are specified. Finally, the standard fashion design workflow at the author's design studio, as guided by the above technologies, is reviewed and discussed.

Keywords: Artificial intelligence; Cognitive technologies; Fashion design; Machine learning; Computer vision; Predictive analytics; Generative
\end{abstract} adversarial networks; Data analytics

\section{Mini Review}

Artificial intelligence (AI) and its related and/or derivative cognitive technologies including: machine learning (ML), natural language processing (NLP), predictive analytics (PA) and others are rapidly and progressively impacting all aspects of fashion practice, and fashion industry in general. From robotics in garment manufacturing to machine vision for smart mirrors, AIderived and related technologies have revolutionized the relevant use cases broadly and drastically. The resulting effectiveness and efficiencies from these applications have in turn attracted more interest and motivation for their further use in other areas such as: virtual fashion assistants and stylists; trend analysis and forecasting; automated customer service and chatbots; etc. Among these applications, AI-driven generative fashion design based on generative adversarial networks (GANs) shows significant potential to complement and enhance the respective creative process [1-3]. Additionally, AI-guided predictive analytics supplemented by data analytics can provide critical input for and augment the related decision-making processes. As an example of this application, the AI-based fashion design process routinely used in practice is briefly reviewed and discussed in the following.

Figure 1 shows the four stages of fashion design workflow at Qiueue Research. The process starts with an exhaustive review and assessment of the design objectives statement (DOS) to ensure its synergy and alignment with the stakeholders' purpose and plans. Essentially, the feedback from previous product rollouts combined with the company's brand position and current competitive analysis define and determine the initial set of objectives. Once reviewed and evaluated, the preliminary DOS will be validated through the second stage of the workflow, that is, the key data analysis (KDA) step, which in turn consists of global style trends (GST), social media consensus (SMC) and relevant market insights (RMI) analyses all three carried out in parallel. The GST analysis, also known internally as "Mode Analysis," as the title indicates ensures that the DOS is on-trend and it involves gathering and analyzing the information, which reflects the global style trends relevant to the subject product as featured by the established designers and design houses. The SMC analysis, aka "Media Analysis," encompasses review and analysis of the relevant data from social media to confirm that the DOS is on-trend with the consumer as well. Finally, the RMI analysis, aka "Market Analysis," is performed to verify that the DOS has the prospect of generating a high-value product. All three components of KDA are carried out using various commercially available AI-driven application programming interfaces (APIs) to seek, find and extract the required data online and with minimal operator intervention. Basically, APIs as computing interfaces, manage and execute the user's requests among multiple software intermediaries. These new and innovative fashion-specific software tools feature efficiencies in data-gathering typically by an order of magnitude better than conventional processes.

Once the KDA step is completed, and the DOS is validated with the prospect of designing and developing a new and popular ontrend and high-value product, the design phase of the project, aka hybrid design development (HDD) is initiated. As shown in Figure 1, the GAN-based fashion design process comprises three steps of generative design synthesis (GDS) algorithmic design optimization (ADO), and hybrid design curation (HDC). 


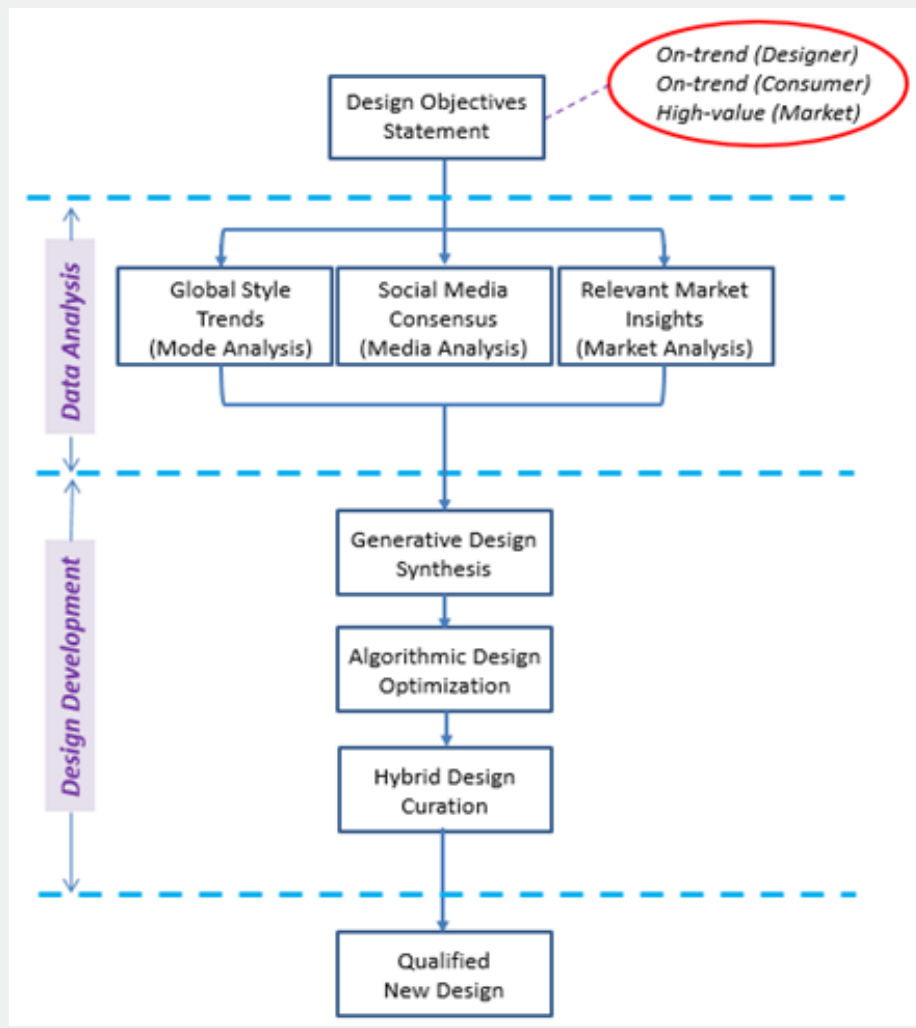

Figure 1: Fashion Design workflow at Qiueue.

The GDS step in turn involves:

a. breaking down the structural and aesthetic elements of the popular designs identified in the previous KDA phase; and

b. synthesizing various designs using these elements.

This step is followed by ADO, in which the GDS designs are algorithmically optimized to feature the maximum number of combined popular aesthetic and structural attributes. Finally, the resulting designs are down-selected and curated by the designer and stakeholders to produce the qualified design for development and production. The above example clearly illustrates the significance of AI in all different aspects of background research data collection and utilization for fashion design including trend analysis; media analysis; and market analysis. It also shows the relevance and application of AI to various facets of the creative process itself.

\section{References}

1. Jiang S, Fu Y (2017) Fashion Style Generator. In: Proc of $26^{\text {th }}$ International Joint Conference on Artificial Intelligence (IJCAI). pp. 3721-3729.

2. Zhu JY, Krähenbühl P, Shechtman E, Efros AA (2016) Generative Visual Manipulation on the Natural Image Manifold. In: Proc of $14^{\text {th }}$ European Conference on Computer Vision (ECCV). pp. 597-613.

3. Kang W, Fang C, Wang Z, Mc Auley J (2017) Visually Aware Fashion Recommendation and Design with Generative Image Models. In: Proc of IEEE International Conference on Data Mining (ICDM). pp. 207-216.

\begin{tabular}{|l|}
\hline Your next submission with Juniper Publishers \\
will reach you the below assets \\
- Quality Editorial service \\
- Swift Peer Review \\
- Reprints availability \\
- E-prints Service \\
- Manuscript Podcast for convenient understanding \\
- Global attainment for your research \\
- Manuscript accessibility in different formats \\
( Pdf, E-pub, Full Text, Audio) \\
- Unceasing customer service \\
Track the below URL for one-step submission \\
https://juniperpublishers.com/online-submission.php \\
\hline
\end{tabular}

